\title{
OS DESAFIOS ÉTICOS NAS ORGANIZAÇÕES MODERNAS
}

\begin{abstract}
Eugène Enriquez
Professor e Diretor do DEA e do Curso de Doutorado em Sociologia da Universidade de Paris VII, Diretor Adjunto do Laboratório de Mudança Social da Universidade Paris VII. Conferencista na EAESP/FGV no $2^{\circ}$ semestre de 1996.
\end{abstract}

RESUMO: O reaparecimento das preocupações éticas traduz o profundo mal-estar de nossas sociedades em conseqüência do triunfo da racionalidade instrumental, que tende a fazer dos seres humanos objetos manipuláveis. Esta perversão da racionalidade manifesta-se particularmente nas empresas que atualmente procuram integrar a preocupação ética dentro de seu funcionamento. Pode-se constatar que, agindo desta forma, elas têm como objetivo, na maior parte das vezes, desenvolver um forte consenso em torno de seus próprios ideais tanto da parte de seus membros quanto do conjunto do corpo social. Devemos nos perguntar quais são os verdadeiros desafios éticos com os quais as organizações modernas se confrontam. Com este objetivo, são revistos os conceitos de ética da convicção, da responsabilidade e da discussão. Uma quarta forma de ética, a ética da finitude, é vislumbrada. As organizações podem Ihe dar um lugar? A questão merece, em todo caso, ser formulada.

ABSTRACT: The reappearance of ethical concerns reflects the profound disquiet in our societies in the wake of the triumph of instrumental rationality, with its tendency of making human beings into manipulatable objects. This perversion of rationality finds its expression particularly in companies, in spite of the fact that they are attempting to integrate a concern for ethics into their functioning at this time. It can be observed that, in doing this, their goal is most frequently to develop a strong consensus around the ideals from which they take their inspiration, both from their members and from the social body as a whole. We must ask what are the real ethical issues that confront modern organizations. To this end, the ethics of conviction, of responsability and of discussion are reviewed here. A fourth form of ethics, the ethics of finitude are considered. Can organizations make a place for this ethics? The question is in any case worth asking.

PALAVRAS-CHAVE: desafios éticos, racionalidade, organizações modernas, responsabilidades.

KEY WORDS: ethical issues, rationality, modem organizations, responsabilities. 
A ética não é um fiacre que se pode mandar parar para subir ou descer à vontade em função da situação.

Max Weber

O homem das civilizações tardias e de lucidez declinante será, a grosso modo, um indivíduo mais frágil.

Nietzsche

O termo ética, anteriormente reservado ao mais árduo labor filosófico e praticamente desconhecido do grande público, apareceu com força na linguagem e na prática das organizações e instituições modernas. A inflacionada utilização desta noção pode ser considerada, à primeira vista, como resultante dos efeitos da moda. No entanto, quando se examina com atenção o movimento do pensamento e da ação, que dá à ética um valor essencial, não se pode deixar de considerar de que se trata, por um lado, de um sinal de mal-estar profundo que afeta a sociedade ocidental e, de outro, uma tentativa de tratar desse mal, quer procurando transformar o sintoma em sinal de cura, quer buscando descobrir suas raízes e seus significados. Este texto tem por objetivo mostrar que somente a segunda abordagem permite compreender as razões pelas quais a questão ética tornou-se uma questão central em nosso tempo e a que ponto ela condiciona o futuro.

\section{O MAL-ESTAR EM NOSSA SOCIEDADE E A ÉTICA}

Iniciamos o assunto afirmando que nossas sociedades, assim como as instituições e as organizações que as compõem, não mais se apresentam, individual ou coletivamente, como legítimas. A mesma desconfiança é colocada também com relação ao Estado, considerado incapaz de propor um grande projeto e de garantir o desenvolvimento econômico e social das principais instituições educativas, terapêuticas e carcerárias que asseguram a regulação social em seu conjunto. Claro que este processo de depreciação não significa que todas essas formas sociais sejam totalmente rejeitadas; simplesmente, elas não parecem ser capazes de cumprir sua missão, que dirá de defini-la de maneira precisa.

O mal-estar é generalizado; sendo reforçado pela ascensão do individualismo e, portanto, por um voltar-se sobre si mesmo e sobre os valores privados, pela impossibilidade de se representar o futuro e pelo desejo correlato de se viver intensamente o presente (culto do efêmero), pela formação de "nichos ecológicos" ou de "tribos" 2 nas quais os indivíduos tentam reconstituir modos de sociabilidade intensa até o instante em que esses lugares não estejam mais em condições de atender seus desejos, seja pela perda do sentido da transcendência ou pela clivagem entre as esferas tecno-econômica, política e cultural... ${ }^{3}$

De nossa parte, pensamos que o estudo da racionalidade ocidental e seu impacto é capaz de esclarecer a dinâmica social atual. Afirmamos, de imediato, que a racionalidade ocidental triunfou no mundo moderno em sua forma perversa através da racionalidade instrumental. ${ }^{4} \mathrm{O}$ desenvolvimento da razão foi acompanhado no século XVIII pelo renascimento da paixão e do valor a ela atribuído.

A razão triunfante não pode se instalar sem efeitos perversos senão respeitando a seguinte condição: admitir que ela é capaz de se colocar a serviço das paixões mais aberrantes ou então, para não cair nesse reverso, ser contrabalançada pela força do fluxo emocional. Com efeito, a razão é essencialmente universalista. $O$ indivíduo pensante é, portanto, uma entidade abstrata e nenhuma distinção é observável entre eles. Cada ser humano, enquanto indivíduo dotado de razão, é - ou deveria ser - estritamente semelhante aos outros. A interioridade de cada sujeito, a alteridade irredutível ao outro, a cultura específica na qual vivem e agem não devem ser levadas em consideração. É somente o reconhecimento do poder das paixões e de inte-
1. DUVIGNAUD, J. La Solidarité. Paris: Fayard, 1986

2. MAFFESOLI, M. Le temps des tribus Paris: Méridiens Klincksieck, 1988.

3. BELL, D. Les contradictions culturelles du capitalisme. Paris: P.U.F. 1979.

4. Em um texto anterior, L' identification comme processus d'intégration/exclusion in: MAPPA, S. L'Europe des douze et les outres, Paris: Karthala, 1992, analisamos mais completamente as conseqüências da racionalidade ocidental. 
5. Tentamos analisar a emergęncia da perversão em nossos estudos Le pouvoir et la mort (1973) e Le gardien des clés (1979), reproduzidos em Les figures du maitre Paris: Arcantère, 1991, como também em nossa obra De la horde à $/$ Etat Paris: Galtimard 1983

6. ENRIOUEZ, E. L'entreprise comme lieu social: un colosse aux pieds d'argile $/ m$ SAINSAULIEU,R. L'entreprise, une affaire de société, Paris: Fondation Nationale des Sciences Politiques, 1991. resses divergentes que assinala a existência de um eu e de um ele, de uma história particular, de uma cultura que possui traços singulares.

Assim, se a paixão é esquecida ou reprimi$\mathrm{da}$, o problema da alteridade dos homens e das culturas é aniquilado. Ora, durante todo o século XIX e ainda mais no século XX, operouse uma dissociação muito clara entre razão e emoção. $O$ resultado não se fez esperar: o mundo criado foi aquele que, em nome da razão (e somente em seu nome), manifestava as paixões, passando a assumir um aspecto ainda mais atuante, visto que o silêncio no qual elas operam (porque elas não têm mais o direito de aparecer publicamente) deixa intacto o seu poder arcaico.

Poderíamos fazer o mesmo diagnóstico no que se refere à paixão dissociada da razão. A paixão termina em paranóia, assim como a razão em perversão. Mas deixemos de lado a primeira. $\mathrm{O}$ fato marcante do século $\mathrm{XX}$ foi a obrigação, não só para as sociedades ocidentais mas também para todas aquelas que a adotaram em seu modo de vida, de se identificarem para poderem continuar seu desenvolvimento ou simplesmente sobreviverem com esta racionalidade dissociada da paixão e negadora de toda subjetividade. É necessário, entretanto, lembrar que o triunfo da razão é um elemento indispensável tanto para a instauração do mercado quanto para a construção democrática. Com efeito, a partir do momento em que o indivíduo é reconhecido como um sujeito de direitos entra, ao mesmo tempo, em competição com os outros que podem fazer prevalecer sua eficácia econômica sobre o mercado de bens e de serviços ou sua vontade política sobre o mercado dos votos. A democracia introduz uma ordem instável que resulta sempre - na teoria - no estabelecimento de um regime harmonioso. Para que tal projeto se realize é necessário que a racionalidade instrumental seja subordinada à racionalidade dos fins. Colocando de um outro modo, os cidadãos podem se perguntar por que e não somente como. Assim, a supremacia da racionalidade traduziu-se pela racionalidade do mercado (e do capitalismo) sobre os valores democráticos.

Atualmente, esse modelo de desempenho, que esteve durante um tempo em concorrência com outros, como o da honra, o do prestígio e o da fidelidade, mas que caracterizou a expansão do capitalismo ocidental, reina absoluto. Pede-se a cada indivíduo que ele se tor- ne um combatente, um herói, um "radar" capaz de se adaptar a todas as circunstâncias, e a populações inteiras que não tenham nada além do êxito econômico e pessoal como palavra de ordem. A conclusão é óbvia: aqueles que podem se adaptar a uma sociedade guiada por estes valores estão seguros de serem reconhecidos como sujeitos e participarem como cidadãos no funcionamento da sociedade. Os outros deverão se contentar (nas sociedades ocidentais) com formas de trabalho subalternas, ou então acabarão por pertencer à categoria dos desqualificados sociais (os chamados assistidos ou marginais).

Claro que não é uma única determinação que está em curso. Seria também necessário perguntar por que razões a perversão tornouse a forma privilegiada das relações humanas nas nossas sociedades. ${ }^{5}$ Seria igualmente necessário examinar em que as dinâmicas próprias das instituições tendem a acelerar entre seus membros a ascensão de um processo de desidealização. Entretanto, o essencial foi dito. Somente um elemento falta ainda: para que a razão instrumental esteja sozinha no comando é indispensável que ela apareça como uma nova forma do sagrado ou, pelo menos, como um novo modelo na instituição onde a razão instrumental fala com mais força, isto é, na empresa. Todos os pensadores estão de acordo que, atualmente, a empresa (mesmo que ela empreste a noção de perfomance do mundo esportivo) tenta impor sua visão tecnicista do futuro humano. Certo que ela não alcança totalmente seu intuito e começa a ser considerada como um "gigante de pés de barro"6 à qual se conferiu um papel mais central na vida social do que aquele que ela pode, dentro dos fatos, assumir.

A empresa, por ter como princial objetivo o alcance de resultados contábeis, introduziu a medida como o único elemento de diferenciação dos seres. Só importam as condutas comparáveis. A cifra torna-se o sinal da excelência dentro da empresa e, progressivamente, no conjunto das organizações.

As conseqüências desta situação são paradoxais:

1. A empresa, trazendo ao seu apogeu os "valores" do capitalismo racional e instrumental, contribuiu enormente para a primazia da técnica sobre o humano e tentou fazer de cada ser um manipulador perverso que não se interessa pelo outro, a não ser que 
favoreça a satisfação de seus desejos. Podese compreender, então, porque são abandonadas as instituições que valorizam a solidariedade, a sociabililidade, quando estas não são mais libido positiva. Seja porque elas parecem remeter a "idéias" ultrapassadas, como por exemplo, o bem comum, o amor comunitário; seja por não produzirem efeitos, já que o resultado de sua aplicação, na realidade, não pode ser objeto de um exame contábil; seja por parecerem incapazes de suscitar paixões arrasadoras e quebrar a muralha da razão instrumental, como a impossibilidade de definir um grande projeto; seja, enfim, por estarem tão contaminadas pelo modelo da empresa com sua dimensão inclusão/exclusão que não conseguem mais provocar o amor e a adesão. Nesse momento, a empresa (e o modelo que ela institui) parece ter alcançado a vitória, porque ela transformou os seres "humanos" em seres "técnicos" ou, dito de outro modo, em puros produtores e consumidores, transformando as relações sociais em relações entre mercadorias.

2. No entanto, somos obrigados a constatar que a empresa, ao se esforçar para vir a ser a instituição divina, é obrigada a se responsabilizar pelo "religioso", que é o próprio fundamento de toda vida social. Ela, então, mobilizará os afetos para poder aparecer como um pólo idealizado que tenta satisfazer o narcisismo de cada um convidando-o a participar da tarefa grandiosa que representa o seu desenvolvimento ininterrupto.Uma tal evolução tem uma explicação muito precisa: se a empresa abrigasse em seu seio somente indivíduos cínicos, com a perversidade maliciosa dos histéricos (portanto, capazes de sedução) ela se arriscaria a cada dia, que cada um, em lugar de se conformar ao ideal da organização, começasse a se opor às suas regras de funcionamento e a colocar, assim, a organização em perigo de morte. $O$ triunfo da técnica se voltaria contra ela mesma. Torna-se, portanto, urgente restabelecer a potência das paixões e das pul- sões somente em benefício da empresa, agora o lugar da socialização e do amor comunitário (edificação de uma cultura de empresa).

3. Entretanto, o movimento da sociedade em direção à racionalidade integral deixa desejos insatisfeitos. Ninguém pode ser feliz com a idéia do destino que aguarda o jogador de xadrez. Não somente porque ele está ameaçado de perder tudo (como em todos os jogos onde não há ganhadores), mas porque ele sabe que, mesmo vencendo uma ou mais vezes, será continuamente obrigado a superar novas provas e, se for ganhador em um dia, pode ser perdedor em outro. Ele também sabe muito bem que seus antigos desempenhos não serão contabilizados ao seu ativo, mas ao seu passivo, sendo a opinião comum "como ele estava bem, antigamente". Neste tipo de jogo, todo mundo é, um dia ou outro, um perdedor. Somente a empresa permanece segura de sua perenidade. Enquanto isso, os homens resistem à instrumentalização. $O$ que faz de cada indivíduo um ser humano e social é a sua capacidade de viver em estado de abstinência, de formular novos desejos, de se deixar levar pela imaginação criadora, que é a origem de toda reflexão e de todo projeto, e de estabelecer com outros relações que intui, e com razão, como sendo essenciais à sua integridade e mesmo à sua vida. Uma lei sociológica bem estabelecida, ainda que continuamente ocultada, sugere que toda ação tem eventualmente como conseqüência o efeito esperado e sempre o efeito inverso. O capitalismo engendra um imaginário social e condutas capitalistas, mas ele produz igualmente as utopias socialistas e o socialismo real. A economia de mercado é necessária à democracia, todavia pode se instaurar num regime ditatorial; o "poder aos soviets" é a origem de um regime que se pretendia igualitário, mas que institui o totalitarismo etc. É então natural que uma sociedade fundada sobre a funcionalidade e sobre a racionalidade desperte entre seus membros desejos de espontaneidade, de 
7. CANETI, E. Masse et puissance. Paris: Gallimard, 1960.

8. MONGIN, 0. La peur du vide. Paris: Seuil, 1991.

9. LE GUYADER, A. Éthique et autorité Texto mimeografado.

10. FABER, E. Main bassé sur la cité. Paris: Seuil, 1991.

11. Idem, ibidem. O autor ampliou a noção de empresa para "responsabilidade ilimitada". atos gratuitos, de tempo perdido, de paixões fortes e de conviviabilidade. É necessário, pois, que uma sociedade baseada na lei do lucro e da eliminação dos mais fra$\cos$ faça surgir as exigências éticas.

Assim, uma sociedade perversa pode, ao mesmo tempo, manter condutas perversas, generalizar a instrumentalização dos indivíduos e tentar transformá-los em uma "massa estagnante", 7 na qual ninguém realiza seu próprio desejo, mas o desejo presumido dos outros, vivendo senão pelo mimetismo e, ao mesmo tempo, por seu caráter excessivo. Esta sociedade pode suscitar entre seus membros a vontade de instituir certas condições de vida, onde a alteridade de cada um seria plenamente reconhecida e onde, segundo a expressão de O'Mongin, se passará "do medo do outro ao medo pelo outro".

\section{A ÉTICA A SERVIÇO DAS ORGANIZAÇÕES}

É interessante notar que os dirigentes das organizações, e em especial das empresas, compreenderam bem esta evolução. Eles também manifestam preocupações éticas. Mas, como eles tinham o desejo de não mudar nada de essencial no funcionamento social que lhes dessem satisfação mantendo-os em funções de poder — nova astúcia da razão instrumental fizeram da ética um meio mais sutil a serviço de um desempenho jamais questionado. Como diz o filósofo Alain Le Guyader, trata-se menos de ética do que de uma etologia que "empresta seus cânones à ciência do comportamento animal para colocar em ação os dispositivos da servidão voluntária assegurando a adesão aos objetivos exclusivos da empresa" (acrescentamos: das organizações e das instituições). ${ }^{9}$

Visto que se trata de uma ética travestida, seria normal que ela passasse em silêncio. Porém, como é praticamente a única que tem o direito de ser mencionada, pois é difundida nos livros, artigos e entrevistas, somos obrigados a levá-la em consideração. Ela funciona segundo um duplo registro: o primeiro, "societal"; o segundo, empresarial. Ambos têm entre si ligações profundas.

\section{O registro "societal"}

A empresa protótipo da organização moderna, novo sagrado (temporário), tenta dar um sentido à sociedade para suprir as deficiências das outras instituições. Para isso ela promove, de acordo com a declaração do grupo de trabalho do CNPF (Confederação Nacional do Patronato Francês) "uma certa imagem de homem firme, ator, criador, responsável', ${ }^{10}$ tanto na empresa como na sociedade. Para construir este novo homem, a empresa deve se tornar cidadã, ou seja, conduzir ações que favoreçam a inscrição dos indivíduos no interior do corpo social.

Dentro deste objetivo, vários meios são postos em ação: desenvolvimento do mecenato; elaboração de produtos que possibilitem a proteção do meio ambiente (a empresa se coloca a serviço da natureza que está em vias de se tornar o novo sagrado criando unanimidade); esforço educativo pela integração dos imigrantes; ajuda ao funcionamento das universidades e das grandes escolas; ação em favor dos bairros; direção de grupos esportivos que têm por objetivo não só o aprimoramento dos desempenhos da equipe mas também a aquisição de um novo prestígio para a cidade, como por exemplo, a equipe de futebol olímpico de Marselha... É inútil continuar a lista de atividades custeadas pelas empresas e às vezes por outras organizações que alonga a cada dia. No entanto, o ponto essencial a ser assinalado é que a empresa difunde uma visão do futuro social (estética, convival e dinâmica), utiliza os meios para realizá-lo e, como consequiência, cria os heróis positivos tais como os concebe. Ela se encarrega não somente do desenvolvimento econômico da nação, mas também do seu desenvolvimento social, psicológico e cívico. Nenhum dos domínios da vida lhe é, a priori, proibido, pois ela se considera com "responsabilidade ilimitada". ${ }^{11}$ É por isso que certos autores não hesitam em dizer que ela se faz "onipotente sobre a cidade" e certos dirigentes de empresa imaginam ter "um destino nacional".

\section{$O$ registro empresarial}

No interior da empresa procura-se fazer com que seus membros, na sua totalidade (e não somente alguns, como há pouco tempo), sintam-se parte integrante da organização ajudando na construção de um projeto da empresa, aderindo à cultura que lhes é proposta, substituindo seus próprios ideais pelo ideal comum definido pela empresa e se submetendo aos 
processos de recalque e de repressão criados pela organização. ${ }^{12}$ A ética parece, no início, fora das preocupações dos dirigentes que desejam essencialmente mobilizar as energias. Mas tal interpretação é enganosa. Para que os indivíduos sejam suscetíveis de exercer seus papéis de heróis positivos é necessário que eles sejam homens de convicção, que tenham senso de responsabilidade, em resumo, como diz o tex to do CNPF já citado, que eles provem ter uma "ética da convicção e uma ética da responsabilidade". Se, portanto, os homens "firmes, criativos" não acreditassem profundamente em suas idéias e não se sentissem responsáveis pela sua ação frente a si mesmos, à organização (e igualmente ao meio ambiente), eles seriam capazes de jogar um jogo individual fatal à sobrevivência da mesma. Ora, as organizações "negam a realidade do tempo $e$ da morte". ${ }^{13}$ Elas se querem imortais, mesmo sabendo que podem desaparecer. Funcionam sob a égide da denegação (eu sei, mas apesar disso...)

\begin{tabular}{|} 
Ser responsável é, \\
então, ser o alvo de \\
toda sanção, \\
vendo-se ao mesmo \\
tempo afastado \\
de qualquer \\
possibilidade de \\
avaliar sua \\
própria ação.
\end{tabular}
que as protege de tomar consciência de suas dificuldades, da finitude necessariamente ligada às suas ações e de seu enfrentamento ao real. ${ }^{14}$ Elas têm, portanto, uma necessidade vital de possuir em seu interior indivíduos capazes de se sacrificarem por elas, homens de dever, de virtude e de virtus (a virtus, para Maquiavel, não é nada mais do que a disposição à coragem). Estes devem, assim, investir a totalidade de sua libido na organização, não obrigatoriamente, porque eles estimam poder receber dela satisfações à altura pela renúncia que aceitaram, mas sobretudo porque acreditam que a organização merece a dedicação que ela reivindica.

Estes "seres-pela-organização" não vislumbram outra vida senão aquela proporcionada pela organização e desde então não buscam mais outros pólos de identificação. Para poder provocar tal amor ou pelo menos suscitar um fluxo de afetividade positiva a empresa deve poder aparecer como um objeto maravilhoso suscetível de provocar entre os indivíduos processos de idealização. Ora, um objeto não é jamais maravilhoso por definição. Para que se torne um icone ou um idolo ele ainda deve poder manifestar alguma virtude. Estas virtudes podem ser divulgadas no mundo das aparências. "Nada falta para melhorar o clima interno da empresa (SAS - Estocolmo): piscina, clube de esportes e mesmo uma pequena orquestra de câmara. /.../ Nada falta (Challenger-Versalhes) para asseguraro conforto dos 2500 colaboradores do grupo que trabalham nos $40.000 \mathrm{~m}^{2}$ de escritório. Salas de conferências modulares, salão de beleza, agências de seguro e de viagens, bancas de jornais, TV a cabo, sem esquecer o ginásio com sauna, sala de bronzeamento etc". ${ }^{15}$ Efetivamente, as organizações atuais cuidam de seu look não só para melhorar sua imagem exterior mas também para dar aos seus membros o sentimento de serem nutridos, protegidos na plenitude de todos, o bem-estar pela empresa. Entretanto, este não é o aspecto mais importante, mesmo que ele seja o mais espetacular. Os dois elementos centrais são a gestão dos recursos humanos e a divisão de responsabilidades. Por estes meios, os dirigentes querem manifestar sua confiança no ser humano. Eles não se dão conta de que se utilizam de um slogan de Stalin de sinistra memória: "O homem, o capital mais precioso". ${ }^{16}$ Eles não percebem o aspecto diretamente instrumental de seu discurso: os homens são administrados, tratados - às vezes melhor, às vezes não tão bem - como estoques dos quais se deve garantir a rentabilidade, como mercadoria (às vezes de péssima qualidade: a expressão "cortar as gorduras" é o sintoma mais evidente) que deve ser utilizada convenientemente ou da qual se deve ser capaz de se desvencilhar. Além disso, se os homens são considerados recursos, não se vê por que milagre eles seriam igualmente reconhecidos como personalidades autônomas, sujeitos de direitos e sujeitos psíquicos que têm palavras a dizer tanto sobre a evolução da organização como da sociedade. Mas é possível ocultar a conotação desagradável dos termos gestão e recursos reforçando que a demanda feita ao homem é de ser responsável. Ora, somente pode ser responsável um sujeito psíquico, um sujeito de direito. A insistência sobre a responsabilidade seria a prova da consideração
12. ENRIQUEZ, E. Imaginaire social refoulement et répression dans les organisations in: Connexions 3, Paris: EPI, 1972. A partir deste texto, numerosos autores tentaram analisar os processos de integração e de submissão ao poder da empresa.

13. Idem, ibidem.

14. ENRIQUEZ, E. Le pouvoir et la mort In: Les figures du maître. Paris: L'Arcantère, 1973.

15. BLOCH \& HABABOU, citados por FABER, E. Op. cit.

16. Quanto mais idealizamos o homem com palavras, mais o rebaixamos com atos. Este atorismo, mil vezes verificado deveria ser reconhecido como uma lei sociológica. 
17. Se não está em questão hipostasiar a natureza porque, deixando de lado (ainda) a floresta amazônica, toda a natureza é produto das ações humanas. É evidente que o problema "natural" é enfim. colocado, e torna-se uma preocupação de todos os dirigentes políticos e não somente de alguns marginais (cf. a Conferência do Rio, 1992).

18. ENRIQUEZ, E. Op. cit. 1991. com o homem em todas as suas dimensões, pela organização. É esquecido nesta afirmação o fato de que a responsabilidade em questão é somente uma responsabilidade organizacional (de modo que a tarefa efetuada favoreça o desenvolvimento da organização; ou, dito de outro modo, que os objetivos alcançados sejam transitivos em relação a um objetivo último) e uma responsabilidade técnica (acionar os meios mais adequados e a competência mais firme para realizar o trabalho com o menor custo possível e de uma maneira excelente). A responsabilidade política (quais são as conseqüências da ação conduzida para a orientação da organização considerando o papel que ela desempenha na dinâmica social?); a responsabilidade social (as decisões tomadas favorecem a autonomia ou a heteronomia dos outros membros da organização?); a responsabilidade cívica (que influência uma ação - ou uma inação - tem sobre a possilibilidade de vida ou de sobrevida dos outros cidadãos?); a responsabilidade ecológica (quais são as incidências das condutas humanas sobre o meio natural, ${ }^{17}$ a fauna, sobre a flora e igualmente sobre as populações próximas ou longínqüas?); a responsabilidade psíquica (que opinião, ou que sentimento, cada sujeito pode formular ou ressentir sobre o valor de seus atos, quaisquer que sejam as sanções positivas ou negativas em que ele possa incorrer?) não são levadas em consideração, na maior parte do tempo, quando as responsabilidades são atribuídas a fatores sociais.

De fato, muitas vezes, quando os homens na organização são designados como responsáveis, isto significa somente que eles são obrigados a prestarem conta de suas decisões do bom andamento dos serviços a seus superiores e de aceitar o julgamento dos mesmos. Ser responsável é, então, ser o alvo de toda sanção, vendo-se ao mesmo tempo afastado de qualquer possibilidade de avaliar sua própria ação. Compreende-se muito bem por que certas pessoas não assumem ou mesmo fujam das responsabilidades que lhes são confiadas pois elas captaram bem a lógica da organização: todo responsável é um constante suspeito e um provável culpado.

No entanto, em vários casos a empresa consegue fazer crer a seus membros que ela é virtuosa, que considera os homens, suas opiniões e sua vida e que pode ser, então, o pólo idealizado por excelência. Ela atinge o obje- tivo jogando com a dupla referência dos grupos e do indivíduo:

a) pela transformação da organização - sociedade em organização - comunidade;

b) pela difusão do culto da excelência que dá satisfação aos desejos narcísicos.

\section{A EMPRESA COMO COMUNIDADE}

Desde o aparecimento da teoria da direção participativa por objetivos é imposta a idéia de que a empresa não é mais um sistema de regras hierarquizadas edificada para obter um certo trabalho e um certo proveito, mas um lugar de cooperação entre membros que formam uma equipe empenhada em atingir um objetivo comum e movidos pelo mesmo ideal. Deste modo, a representação de uma organização como sociedade onde as condutas humanas são definidas por regras imperativas e que se produzem num mundo de relações formalizadas é atenuada para dar lugar à representação de uma comunidade de seres fraternais que estabelecem relações convivas, que são responsáveis por seus atos e desejam o bem comum.

Que as organizações não tenham sido jamais lugares unicamente formais, funcionais e impessoais os teóricos bem o sabem e mostram que mesmo nas burocracias mais rígidas existiam relações "informais", reagrupamentos que se estabelecem baseados em afinidades eletivas, sobre a necessidade do trabalho, sobre o contorno de regras ou sobre a defesa coletiva. Toda organização guarda em seu interior comunidades variadas, micro-culturas se constituindo como um lugar de vida e não como um simples lugar de trabalho. Mas, passar desta constatação à afirmação segundo a qual a organização tornou-se uma comunidade funcionando sem um aparato de poder separado, instituindo uma certa orientação e um estilo de vida determinado, é desdenhar da existência de estratos diferentes preenchendo funções mais ou menos prestigiosas dentro de relações de consenso e de conflito. No entanto, é justamente esta ideologia que é o fundamento da administração participativa. E se os membros da organização muitas vezes a aceitam é por que ela anuncia que a organização não pode existir "sem que indivíduos se situem enquanto sujeitos humanos, isto é, enquanto atores que devem se exprimir, mestres de seus desejos trabalhando afirmativamente para $o$ sucesso do conjunto". ${ }^{18}$ Como é difícil resistir 
a tal apelo, ainda mais sabendo, que o imaginário social igualitário da comunidade cria um mundo de plenitude que permite a cada um crer que sua necessidade de segurança pessoal estará satisfeita!

\section{O CULTO DA EXCELÊNCIA}

Essa necessidade de segurança pessoal se intensifica ainda mais quando se instaura o culto da excelência. Excelência, certamente, dos líderes carismáticos ou estratégicos que favorecem a identificação com sua própria pessoa. Mas excelência igualmente de cada um, já que não importa qual "homem sem qualidades" ${ }^{\prime 19}$ pode, à condição de querer ser brilhante a qualquer preço e, portanto, de se devotar de corpo e alma, tornar-se um dia um ser tão excelente que os outros o admirarão e imitarão. Aqui alcançamos o heroísmo para todos! Admirarse-á o brio deste novo culto, que sabe prender com uma habilidade sem igual os indivíduos nas armadilhas de seus desejos narcísicos. Como recusar-se a ser um herói, um homem capaz de "sair da formação coletiva", ${ }^{20}$ já que tal futuro está ao alcance de qualquer um?

O único problema é que é impossível que todos sejam vencedores. Em toda a batalha existem vencedores e vencidos. Ninguém acreditará que nas organizações somente se pratiquem jogos à somatória não-nula nos quais todos devem ganhar. Os cadáveres, reais ou simbólicos, acumulados há gerações atestam a realidade muitas vezes violenta da vida organizacional. Além do mais, a concepção proposta do herói é fundamentalmente falsa. $O$ homem heróico foi, em todos os tempos, um ser apto a pensar de modo solitário (ou com alguns), a ser contra o pensamento (ou mais exatamente a doxa) gregário da "maioria compacta", ${ }^{21}$ capaz de assumir riscos ("No meu trabalho eu arrisco a minha vida e a minha razão perde-

RAE • v. 37 - n. 2 - Abr./Jun. 1997 se pela metade": são as últimas palavras escritas por Vincent Van Gogh a seu irmão Théo) procurando o conflito e não o compromisso, mostrando consistência ${ }^{22}$ e sabendo que não devia esperar dos outros, que lhe seguiriam um dia, nem amor nem reconhecimento. Estamos bem longe destes "heróis portáteis" que, segundo o bem-humorado Andy Warhol, serão célebres "quinze minutos em sua vida", pois se deve deixar seu lugar aos outros, heróis “frágeis", como já havia percebido Nietzsche. Enfím, não se pode esquecer que o verdadeiro herói, aquele que se tornará um pai simbólico, que provocará a identificação e criará sujeitos que busquem a autonomia é marcado, um dia, pelo fracasso ou pela morte. Moisés não viu a terra prometida, Cristo foi crucificado, Maomé teve que emigrar para Medina. Em nossos dias, mais prosaicamente, Churchill foi desdenhado pelos seus, enquanto De Gaulle teve que se retirar e, tanto Gandhi quanto Martin Luther King foram assassinados. Os falsos heróis que morreram de suas belas mortes (Stalin, Mao) são pessoas que construíram seus impérios e suas empreitadas sobre o sangue de seus concidadãos.

Pode-se agora considerar a que ponto o imaginário da comunidade e da excelência é um imaginário ilusório, onde o objetivo é fazer indivíduos conformes que respeitem o ideal da organização. Neste jogo, os indivíduos perdem cada vez que eles pensam ganhar. $O$ único vencedor é a organização que recebe, assim, um acréscimo de legitimidade, que continua a se acalentar de sonhos de imortalidade e que crê, desta maneira, não ser atingida pela crise que afeta o conjunto das instituições.

Assim sendo, conforme já foi indicado, as organizações, apesar de seu desejo de ascender ao estatuto de instituição divina, são afetadas, também, pela crise da legitimidade e pela ascensão do individualismo perverso que pa-
19. Título do livro de MUSIL, R. Ohomem sem qualidades. Lisboa: Livros do Brasil, 1952.

20. FREUD, S. L'homme Moïse et la religion monotheiste. Tradução recente. Paris: Gallimard, 1986.

21. Expressão de $H$. Ibsen, freqũentemente citada por Freud, particularmente em Moisés e o monoteismo, 0p. cit.

22. Cfr. MOSCOVICI, S. Psychologie des minorités actives. Paris: P.U.F., 1971. 
rece ter, a princípio, prestado socorro e contribuído ao seu sucesso. As organizações, cada vez que se nutrem de vitórias, estão próximas do fracasso. Há verdades que devem ser repetidas incansavelmente, pois a verdade provoca uma ferida narcísica e continua com dificuldades para se fazer ouvir.

\section{OS VERDADEIROS DESAFIOS ÉTICOS}

Se a ética não pode se colocar a serviço das organizações, isto não impede que as organizações modernas possam ocultar o problema da ética sob pena de serem abandonadas ou traídas por seus membros, tornados mais perversos que elas próprias e deixando-se levar ao não-senso, uma vez que mais nada (nenhuma organização, nenhuma doutrina) é capaz de dar um sentido à suas vidas.

Costuma-se, quando se evoca a questão da ética, a partir de Weber, distinguir ética da convicção (à qual Kant deu a formulação mais clara) de ética da responsabilidade.Deve-se acrescentar às duas, ao se considerar a obra de $\mathrm{J}$. Habermas, a ética da discussão. Estes três tipos de ética servirão de fio condutor ao propósito que segue. Questionaremos se a elaboração de uma quarta categoria não seria necessária para cercar verdadeiramente os desafios atuais.

A ética da convicção é uma ética do tudo ou nada. Não se trata de introduzir nuances. Se a injunção é "oferecer a outra face", deverse-á oferecê-la em todas as circunstâncias. Se o outro não deve ser jamais tratado como um meio mas como um fim, isto significa a recusa geral e definitiva de toda tentativa de instrumentalização dos seres humanos. Assim, uma convicção não se negocia. Além do mais, esta ética não se preocupa com as conseqüências dos atos. Se "oferecer a outra face" é dar o poder às forças do mal, que importa! Esta ética se interessa somente pelo fim último. Todos os meios são bons quando permitem alcançar o fim desejado.

Tal ética coloca um problema evocado por Max Weber: "Para atingir fins 'bons' somos, na maior parte do tempo, obrigados a contar por um lado, com os meios moralmente desonestos ou, pelo menos, perigosos; de outro, com a possibilidade ou mesmo a eventualidade das conseqüências deploráveis. Nenhuma ética no mundo pode dizer em que momento ou em que medida um fim moralmente bom justifica os meios e as conseqüências moralmente perigosas". ${ }^{23}$ No entanto, tais preocupações estão ausentes dos homens de convicção. De fato, eles são muitas vezes, como disse Freud, "iluminados, visionários, homens que sofrem de ilusão, neuróticos e loucos. Em todos os tempos [eles] desempenharam um grande papel na história da humanidade. Tais pessoas exerceram uma influência profunda sobre seu tempo e sobre os tempos ulteriores, dando um grande impulso a importantes movimentos culturais e fazendo grandes descobertas. Eles puderam executar tais façanhas, de um lado, graças à parte intacta de sua personalidade, quer dizer, apesar de sua anomalia; mas, de outro lado, foram os traços patológicos de seu caráter, seu desenvolvimento unilateral, o reforço anormal de certos desejos, o abandono sem crítica ou sem freio a um único objetivo que lhes deram o poder de arrastar os outros no seu rastro e de vencer a resistência do mundo". ${ }^{24}$ Tais indivíduos de exceção escolhem seus caminhos e não mudam. De fato, eles não percebem que:

a) ao utilizar meios discutíveis ou empregar os mesmos meios dos adversários que combatem não podem atingir o fim vislumbrado, estando este definitivamente contaminado pelos meios. Eles não querem ver que o que importa no social não é a intenção, ainda que ela seja tão louvável, mas os meios que impõem, sempre e em qualquer lugar, sua ditadura. É por esta razão que as revoluções, quando bem sucedidas (a Revolução Francesa, não esqueçamos, não foi bem-sucedida e é por esse motivo que ela constitui ainda uma referência), não são portadoras de "um amanhã que canta", mas de escravidão generalizada e genocídio. Os benfeitores da humanidade, quando não se questionam sobre os meios, são coveiros;

b) ao não desejar colocar a questão das conseqüências de uma ação, os sujeitos de exceção não podem tomar consciência de seus erros de apreciação, ficando obrigados a imputar os resultados não previstos a culpados que eles escolhem. O homem de convicção é um ser que cria, sem dificuldades, vítimas tipo bodes expiatórios.

E, portanto, sem homens de convicção, sem esses seres movidos por uma "idéia fixa", lu- 
tando contra ventos e marés, crendo no inacreditável, pensando que as montanhas podem se deslocar, batendo a cabeça contra as paredes com a certeza de as derrubar, ${ }^{25}$ habitados por um um fervor sagrado, o mundo não seria nada além de "um longo rio tranqüilo" e a vida, uma sucessão de instantes monótonos. Os grandes homens, para se tornarem criadores de história ${ }^{26}$ devem abalroá-la, ainda que fracassem ou que sejam repudiados. Moisés, Cristo e Maomé não eram criaturas ternas, dispostas a compromissos, mas justamente o contrário. Guardadas as proporções, os grandes chefes de empresa são frutos da mesma árvore. $\mathrm{O}$ problema é que se pode esperar do homem de convicção tanto o melhor como o pior.

A ética da responsabilidade se apresenta de outro modo. Não que os homens de convição não tenham o senso da responsabilidade. Pelo contrário, eles se encarregam da transformação do mundo e sabem que seus atos serão um dia julgados. Mas eles não escolhem suas condutas em função de sua probabilidade de sucesso. Por outro lado, o homem movido por uma ética de responsabilidade estimará que consequiências são imputáveis a sua própria ação, à condição que ele as poderá prever ${ }^{27} \mathrm{e}$, portanto, colocarse-á na condição de antecipar os resultados prováveis. O homem "de responsabilidade" é, pois, fundamentalmente um "político" que sabe que o melhor é o inimigo do bem e ainda, aquele que considera o contexto ao tomar as decisões aceitáveis para a maioria. A ética da responsabilidade é exigente. Com efeito, como já dito anteriormente, o homem tem sempre responsabilidades diversas, organizacional, técnica, política, social, cívica, ecológica, psíquica e sendo difícil para ele assumi-las em conjunto, pois algumas podem apresentar aspectos contraditórios, como por exemplo, um funcionário do departamento pessoal deverá considerar sua responsabilidade técnica e organizacional na aplicação do fluxo de demissão do pessoal "excedente" em detrimento de sua responsabilidade social e cívica. $\mathrm{O}$ homem de "res- ponsabilidade" deverá, então, arbitrar entre as responsabilidades que ele assume e aquelas que ele recusa. Ele terá, às vezes, tendência a considerar as responsabilidades tais como elas são definidas pela organização. Poderá, a partir disso, saber exatamente quais sanções positivas ou negativas irá receber colocando-se numa situação de segurança máxima. No entanto, isto não é tão simples. Em todos os tempos, certos homens fizeram prevalecer, por exemplo, sua responsabilidade social ou psíquica sobre sua responsabilidade organizacional. O problema é bem mais sério em nossos dias, já que as organizações são mais complexas e formulam exigências variadas a seus colaboradores. A emergência de uma exigência ética na organização faz precisamente com que as responsabilidades política, cívica, ecológica e psíquica sejam cada vez mais asseguradas, não porque o dinamismo da organização exige, mas porque é impossível, a quem quer que seja, ignorá-las, sob o risco de ver triunfar unicamente o cinismo perverso. É claro que a tentação do cinismo, da instalação do não-senso e do individualismo egoísta existe, como mostrou o início deste texto. Mas se eles invadissem todo o campo, a organização e a sociedade não teriam qualquer legitimidade. Toda autoridade seria contestada, a angústia ligada à perda dos referenciais predominaria sem contenção e o reconhecimento do eu e dos outros se tornaria impossível. É por isso que as responsabilidades se multiplicam. Não há mais empresas que possam, legitimamente, desembaraçar-se de toda preocupação ecológica. Não há organização onde a preocupação social - principalmente as empresas japonesas - esteja ausente etc.

Ainda é muito cedo para dizer qual hierarquia de responsabilidades será aceita por nossa sociedade. Porém, pode-se adiantar que o estabelecimento de tal hierarquia é justamente o desafio fundamental das lutas constituídas por diversos grupos sociais e dos conflitos internos que devem travar todo ser humano. $E^{\prime}$
25. Um autor como M. Crozier. particularmente reservado em relação a ações desmesuradas, nota, com humor, que, às vezes, a cabeça não fracassa e as paredes se quebram. Cfr. CROIZIER \& FRIEDBERG. L'acteur et le système. Paris: Seuil, 1986.

26. ENRIQUEZ, E. Individu, création et histoire. Connexions 44, EPI.

27. WEBER, M. Op. cit., p. 192. 
28. HABERMAS, J Raison et légitimité Paris: Payot, 1978, p. 150.

29 communication. Paris: Cerf, 1987, p. 87

30. FERRY, L. Les puissances de l'experience. Paris: Cerf, 1991, p. 172. por esta razão que o tema da responsabilidade, fora de toda pesquisa de culpabilidade, tornouse o termo (modelo) central de nossas sociedades, ainda que elas não saibam muito bem como tratá-lo. De toda maneira, qualquer que seja a lista, é evidente que um dos problemas essenciais que a sociedade deverá enfrentar concerne não somente ao futuro mas igualmente ao passado. Com efeito, os seres humanos e sociais não são somente responsáveis frente às gerações futuras pelo peso de suas ações presentes mas também pela maneira como eles tratam o passado, como eles registram a história, a aceitam e a deformam. Por exemplo, a ocultação durante quase 50 anos do período de Vichy, na França, favoreceu a eclosão do fenômeno Le Pen e os sucessos da Frente Nacional da mesma maneira que a ignorância dos crimes nazistas na R.D.A.- República Democrática Alemã (os dirigentes afirmavam que os nazistas vinham todos da R.F.A.- República Federal Alemã) facilitou a implantação de um neo-nazismo na Alemanha do Leste. O reprimido retorna sempre (Freud já havia exposto esta idéia com força) e com mais virulência quanto mais intensa tenha sido a repressão. Não é possível, desse modo, responsabilizarse pelo presente e pelo futuro se ou quando se quer esquecer o passado. Ser responsável é encarregar-se das dívidas (e dos créditos) das gerações passadas para não cair num mecanismo de repetição do qual as gerações futuras só teriam a sofrer.

Com J. Habermas desenvolveu-se uma ética da discussão. Ele coloca a posição da intersubjetividade. É essencial que os homens possam trocar argumentos racionais referentes a seus interesses dentro de um espaço público de livre discussão. Assim, cada um é considerado como um ser autônomo, dotado de razão, que pode dar sua opinião. Da discussão, onde somente as propriedades formais são definidas, surgirão novas normas e interesses universalizáveis. Habermas resume seu pensamento nestas linhas: "A vontade formada de modo discursivo pode ser dita 'racional' porque as propriedades formais da discussão $e$ da situação de deliberação garantem suficientemente que um consenso não pode nascer senão sobre interesses universalizáveis, interpretados de modo apropriado, o que entendo como necessidades que são compartilhadas de modo comunicacional. A barreira, representada um tratamento decisionista(autoritário) das questões práticas, é ultrapassada desde que se solicite à argumentação examinar $o$ caráter universalizável de interesses em vez de se resignar diante do pluralismo, em aparência impenetrável, dos valores últimos (ou dos atos de fé ou das atitudes)". ${ }^{28}$

O que pressupõe esta posição é que a ética da convicção (onde cada um defende suas posições e não muda) cederá lugar à ética da discussão, cada um podendo fazer concessões e onde as normas criadas serão aceitáveis por todos. Com efeito, para Habermas, toda norma universalmente observada terá, de maneira previsivel, conseqüencias e efeitos secundários que poderão ser aceitos sem exigências por todas as pessoas envolvidas dentro do projeto de satisfazer os interesses de cada um". ${ }^{29}$

Pode-se reconhecer no pensamento de Habermas uma forte semelhança com o pensamento psicossociológico, em particular com aquele de Lewin; a diferença essencial é que o consenso obtido não será sobre a base "dos conteúdos axiológicos que remetem às convicções antropológicas das partes envolvidas, mas sobre os termos processuais de um compromisso entre estas convicções". ${ }^{30}$ No entanto, além das diferenças, a idéia central é que se os indivíduos ao comunicarem-se entre si respeitando as exigências de validade de um discurso que tem um sentido, que exprime a busca da verdade, que é sincero e demonstra justiça normativa, estão em condições de chegar a um acordo e de encontrar soluções justas e eficazes. Claro que Habermas não cai na utopia (Lewin também não) segundo a qual os indivíduos chegarão sempre a formular interesses universalizáveis. $\mathrm{O}$ que lhe parece essencial é definir as condições que permitem a todos os seres humanos utilizar sua racionalidade consensual e comunicativa e assim existir enquanto tais.

Mesmo se uma tal perspectiva parece refletir tendências evidentemente consensuais de nossa sociedade aparecendo como pouco suspeita, da mesma forma que a racionalidade sem paixão pode tornar-se perversa, deve-se admitir seu interesse, visto que ela evoca a eminente dignidade do homem como indivíduo capaz de reflexão, de expressão e confronto com outros. Se esta perspectiva é menos original do que parece (Merleau-Ponty já tinha exposto há bastante tempo que a objetividade vinha da subjetividade) ela nos faz, pelo menos, sentir a impossibilidade da formulação de uma 
ética que não esteja fundada sobre a reciprocidade. Nisto nos permite compreender melhor que a participação tanto nas organizações como na sociedade implica considerar as idéias do conjunto dos indivíduos situados num plano de igualdade. Ela dispensa todos os tipos de manipulação, mas não poderá ser plenamente satisfatória, pois não visualiza os homens em seu aspecto passional nem tão pouco seus interesses totalmente contraditórios, eliminando os efeitos da pulsão de morte nas organizações e nas instituições. É possível, então, expor uma quarta forma de ética que, provisoriamente, será nomeada ética da finitude. Segundo tal concepção, as condutas humanas serão definidas:

a) pelo seu papel na rigidez, na homogeinização e na destruição possível das estruturas e dos homens, ou, ao contrário, por sua espontaneidade e capacidade de favorecer o processo de autonomização;

b) por sua capacidade de considerar não somente a atividade do pensar e do prazer a ela vinculado mas igualmente a das paixões, a dos medos, a dos sofrimentos, a das limitações que afetam toda vida;

c) por sua atitude e sua coragem de aceitar as feridas narcísicas, a finitude e a mortalidade, de se submeter ao trabalho de luto e de se confrontar continuamente com a pulsão de morte em seus aspectos auto e alter destruidores.

Outros termos poderiam ter sido utilizados, mas o que eles evocam estão contidos nas três primeiras formas de ética: a coragem na ética da convicção, o futuro das estruturas e dos homens na ética da responsabilidade, a autonomia e o reconhecimento da alteridade na ética da discussão. Por outro lado, nenhuma das três primeiras formas de ética visualiza a aceitação da impotência, a tomada de consciência dos limites, o questionamento da identidade e do narcisismo da morte, a consideração das consequiências nefastas sobre o futuro do gênero humano, a convivência de cada um com a morte que carrega em si e que pode projetar sobre os outros. É então que o sujeito se situa tanto como portador de vida e de morte, como egoísta e altruísta, como ser de razão e de paixão que pode ter convicções fortes, mas

RAE • v. 37 - n. 2 - Abr./Jun. 1997 sobretudo que é capaz de mudar, se na troca conseguir se transformar, a saber, portanto, pensar sozinho e com os outros, a se conceber como responsável sem ser bloqueado pelo medo das responsabilidades, a fazer passar suas idéias (ou aquelas de outro que ele aceitou) interrogando-se sobre sua deformação possível pela escolha de certos meios, sabendo que as conseqüências imprevistas serão mais facilmente encontradas que as consequiências previstas. Tal sujeito é capaz de sublimação, isto é, de procurar-se a si mesmo nos outros e aos outros em si mesmo ${ }^{31}$ numa busca permanente da verdade.

Assim, a ética da finitude pode integrar as três primeiras formas de ética. Claro, cada uma apresenta características não redutíveis às outras. Mas a ética da finitude opera precisamente um trabalho de transformação destas características para torná-las pragmaticamente compatíveis. É pelo fato de ter uma idéia dos seus próprios limites que o homem pode ser um "homem de convicção" aceitando entrar em comunicação com os outros; também, por conhecer as capacidades mortíferas das discussões ele as aceita até o momento em que compreende que a negociação conduzida ininterruptamente faz com que perca sua alma; e, finalmente, por que persegue objetivos que quer verdadeiramente realizar (e não se contenta em proclamá-los), estando atento à escolha dos métodos para atingi-los. Portanto, autonomia e heteronomia não se oporão mas se completarão, assim como comunicação e solidão, força de vontade e percepção das exigências. Tal ética, que deverá um dia ser formulada mais claramente, é particularmente exigente. Ela requer homens dotados de paixão, sem a qual a imaginação não pode emergir; de julgamento, sem o qual nenhuma realização é possível; de referência a um ideal, sem o qual o desejo não abandona sua forma arcaica; de aceitação do real e de suas obrigações, sem as quais os sonhos mais ambiciosos se transformam em pesadelo coletivo. Ela também requer que as organizações sejam um lugar onde a manipulação é banida e os esforços de todos na construção da organização e na edificação do social sejam reconhecidos. Nós ainda estamos longe da meta. Mas, enquanto as organizações preferirem homens que as idealizem a homens "de sublimação" elas continuarão a serem construídas na areia e desaparecerão lentamente, sem chegarem a perceber as razões de seu infortúnio.
31. ENRIQUEZ, E. Chemins vers l'autre, chemins vers soi. In: MAPPA, S. Ambitions et illusions de la cooperation Nord-Sud. Paris: L'Harmattan, 1990.

Artigo originalmente publicado na revista Sociologie et Sociétés, v. XXV, n. 1, p. 25 - 38, printemps 1993, sob o título Les enjeux éthiques dans les organizations modernes. Tradução de Maria José Tonelli, Professora do Departamento de Fundamentos Sociais e Jurídicos da Administração da EAESP/FGV. 